\title{
PANDEMIE E VIRUS EMERGENTI: NUOVE SFIDE E ANTICHE PAURE
}

\author{
GIOVANNI MAGA (*) \\ Nota presentata dal s.c. Giuliano Gasperi \\ (Adunanza del 21 dicembre 2017)
}

SunTO. - Le epidemie di AIDS, SARS, influenza aviaria, MERs-CoV and SARS-CoV2 sono esempi di infezioni virali che, a partire da piccoli focolai in regioni circoscritte, hanno fatto il giro del mondo. La notizia della scoperta di virus capaci di infettare l'uomo, provenienti da remote regioni del globo e dai nomi esotici come Nipah, Chikungunya, Hendra, non è più relegata ai bollettini medici specializzati, ma viene ripresa dalla stampa mondiale. Questo perché è ormai diffusa la consapevolezza che ogni ogni focolaio, per quanto piccolo e distante, può dare inizio a un incendio inarrestabile. Affrontare queste situazioni richiede la capacità di fare previsioni, di effettuare proiezioni attendibili di dati, di ipotizzare scenari possibili. In altre parole occorrono esperienza e conoscenze approfondite. Per combattere $i$ virus, dunque, è di fondamentale importanza capire come si trasmettono, moltiplicano, evolvono, da soli o per effetto dell'impatto sull'ambiente delle attività umane. Sulla base di queste conoscenze, è possibile non solo ideare farmaci e vaccini per alleviare l'impatto delle infezioni virali sulla salute dell'uomo, ma anche manipolare geneticamente questi parassiti intracellulari per applicazioni di terapia genica.

$$
* * *
$$

ABSTRACT. - The epidemics of AIDS, SARS, avian flu, MERS-CoV and SARS-CoV2 are examples of viral infections which, starting from local outbreaks, spread in many different countries or even became pandemics. Reports of novel viruses emerging from remote areas of the world and able to infect the human population, are not anymore confined to medical bulletins, but are being found everyday in newspapers and public media. This, because it is now well understood that every outbreak, small and remote it may be, can rapidly evolve into a worldwide health emergency. Dealing with such situations requires

(*) Istituto di Genetica Molecolare IGM-CNR, Pavia, Italy.

E-mail: giovanni.maga@igm.cnr.it 
high forecasting ability starting from the available data and deep knowledge of the many factors influencing the spread of a viral outbreak. In turn, such ability stems from the study of the life cycle and pathogenetic mechanisms of the viruses. Understanding the biology of viruses and the relationships between emerging viral pathogens and the anthropic influences on the environment is the key to develop new drugs and vaccines, but also to genetically manipulate viruses for gene therapy applications.

\section{INTRODUZIONE}

I virus sono antichi abitatori della Terra, forse fin dall'origine della vita, ma ancora non sappiamo rispondere del tutto a domande fondamentali quali: i virus sono vivi? Da dove vengono? Come ne nascono di nuovi?

In un mondo sempre più affollato, mobile e veloce, le opportunità che l'uomo incontri nuovi virus si moltiplicano. Epidemie come l'AIDS, l'influenza aviaria, Ebola o la SARS preoccupano gli esperti di salute pubblica: ma quali forze le hanno scatenate?

Nell'immaginario collettivo, i virus sono inestricabilmente legati a suggestioni negative: malattie, epidemie, bioterrorismo. Una visione giustificata ampiamente dal fatto che alcune delle malattie più diffuse e difficili da combattere a livello mondiale sono causate da virus e ulteriormente amplificata dal tono spesso terrorizzante che i mezzi di comunicazione riservano alla cronaca di episodi epidemici anche in paesi lontani.

A questa prospettiva antropocentrica, tuttavia, deve oggi sostituirsi una visione più globale, incentrata sul concetto di base che i virus, al pari di ogni altra forma biologica, sono parte integrante dell'ecosistema globale. I loro cicli vitali, quindi, sono strettamente connessi a quelli degli altri esseri viventi, in una rete di interdipendenza indissolubile. I virus sono parte fondamentale della vita sulla Terra: solo partendo da questo assunto fondamentale è possibile studiare e comprendere le complesse dinamiche che sottendono alla loro evoluzione e diffusione [1].

\section{CARATTERISTICHE BIOLOGICHE DEI VIRUS E LORO POSSIBILE ORIGINE}

I virus sono parassiti endocellulari obbligati, devono cioè penetrare all'interno di una cellula per potersi riprodurre. I virus sono elementi acellulari: la loro struttura fondamentale è costituita da un acido nucleico (RNA o DNA) che contiene il patrimonio genetico, circondato da un 
involucro proteico detto capside. Alcuni virus presentano poi un ulteriore rivestimento proteinaceo, detto matrice, sul quale prende contatto una membrana lipidica, derivata dalla membrana della cellula infetta, che prende il nome di tunica o "envelope". La particella virale così composta è detta virione. I capsidi virali hanno strutture altamente regolari, riconducibili a due simmetrie fondamentali: icosaedrica ed elicoidale. Questa caratteristica risponde a due esigenze: la necessità di compattare l'informazione contenuta nello spazio genetico ristretto caratteristico della maggior parte dei virus, che possiedono genomi di ridotte dimensioni, e la ottimizzazione del processo di assemblaggio dei capsidi, che avviene all'interno della cellula ospite. Le strutture di tipo icosaedrico od elicoidale, possono essere facilmente ottenute dall'assemblaggio di una o poche (due-tre) proteine in unità strutturali di ordine superiore che, avendo un'energia minima, possono anche autoassemblarsi senza bisogno di reazioni enzimatiche a supporto del processo [2].

Le dimensioni delle particelle virali vanno da $20 \mathrm{~nm}$ a circa 0.5 $\mu \mathrm{m}$. Queste particelle, dette virioni, sono totalmente inerti nell'ambiente esterno, ma quando entrano in una cellula ne prendono il controllo, trasformandola in una fabbrica di virus. Durante questo processo, il patrimonio genetico dei virus (ovvero il loro RNA o DNA) può mescolarsi a quello della cellula ospite, oppure può inglobare geni cellulari, acquisendo così nuove proprietà e consentendo il trasferimento di geni da una cellula all'altra.

L'ingresso dei virus in una cellula è mediato dalle interazioni molecolari tra le proteine virali presenti alla superficie del virione e le proteine cellulari presenti sul lato esterno della membrana plasmatica [2]. Si distinguono due principali meccanismi di penetrazione delle particelle virali all'interno della cellula:

- Endocitosi, in cui il virione viene racchiuso in una vescicola formatasi dall'invaginazione della membrana plasmatica cellulare nel punto in cui il virione la contatta e che successivamente viene internalizzata nel citoplasma.

- Fusione, processo esclusivamente a carico dei virioni dotati di tunica, in cui la membrana lipidica esterna della particella virale si fonde alla membrana plasmatica cellulare, liberando il capside nel citoplasma.

Una volta all'interno della cellula, il virione va incontro a spoliazione, ovvero disgregazione, del capside e l'acido nucleico virale, così liberato, viene trascritto, tradotto in proteine e duplicato, al fine di 
costituire nuovi virioni che poi usciranno dalla cellula. Il processo di fuoriuscita può essere mediato da gemmazione, in cui la particella virale acquisisce il rivestimento esterno lipidico da una porzione della membrana cellulare; da esocitosi, in cui il virione viene esportato all'esterno da una vescicola di trasporto; o per lisi cellulare che porta alla disgregazione della cellula stessa con liberazione di tutti i suoi componenti interni, incluse le nuove particelle virali.

Un elemento che caratterizza i virus è la loro capacità di infettare qualsiasi cellula vivente. Non esiste organismo vivente che non sia infetto da virus. Questa osservazione, da sola, suggerisce un'antichità estrema dei virus. Infatti, solo ipotizzando che questi parassiti siano comparsi all'epoca dei primi elementi cellulari batterici, oltre 3 miliardi e mezzo di anni fa, si può spiegare come abbiano potuto adattarsi a interagire con le cellule di organismi di ogni livello di complessità: dai semplici batteri, alle piante, agli animali. Attualmente esistono due ipotesi principali sull'origine dei virus [3]:

- Ipotesi riduzionista: i virus sono cellule degenerate che hanno perso la capacità di vita autonoma e sono divenute parassiti cellulari. Un meccanismo simile ha portato durante l'evoluzione alla generazione dei mitocondri a partire da antichi batteri endosimbionti.

- Modello fuga dalla cellula: i virus derivano da elementi genetici cellulari che hanno acquisito una certa autonomia. Tali elementi genetici mobili sono ancora presenti nella moderna biosfera, come ad esempio i plasmidi batterici e i trasposoni.

Indipendentemente dal preciso meccanismo evolutivo, $\mathrm{i}$ virus appaiono comunque elementi molto antichi della biosfera, apparsi prima della separazione delle due principali linee evolutive (procarioti e archea/eucarioti).

\section{ABBONDANZA E DISTRIBUZIONE DEI VIRUS NELLA BIOSFERA E LORO IMPORTANZA NELL'EVOLUZIONE DELLA VITA}

Un primo aspetto che riflette la pervasività dei virus nell'ambiente è la loro numerosità. Si stima che solo nelle acque degli oceani siano presenti $10^{30}$ virus e numeri simili caratterizzano tutti gli altri ambienti. Oggi sono note alla scienza solo lo $0.1 \%$ di tutte le specie virali esistenti. L'organismo umano ospita stabilmente migliaia di miliardi di virus. Un grammo di feci ne può contenere fino a $10^{11}$. Si tratta di virus residenti 
che non causano patologie, la maggior parte dei quali infetta i batteri dell'intestino umano. Il viroma umano, come viene definita la popolazione virale residente, è essenziale per il corretto sviluppo del sistema immunitario e per l'equilibrio della flora batterica intestinale [4].

Lo stretto connubio tra esseri viventi cellulari e virus è riflesso anche dal ruolo fondamentale che i virus hanno avuto nel plasmare la struttura genetica dei viventi, contribuendo così alla loro evoluzione. Tracce di questi trasferimenti genici si trovano nel genoma di tutti gli organismi, uomo compreso. Il genoma umano è infatti costituito per il $30 \%$ da sequenze derivanti da antichi virus, che durante l'evoluzione hanno mescolato i loro geni con quelle degli organismi della nostra linea evolutiva. Un esempio di quanto questo scambio di geni sia stato fondamentale per l'evoluzione è dato dalla proteina sincitina, essenziale per lo sviluppo della placenta. In origine era la proteina del rivestimento esterno di un virus, acquisito dai progenitori dei placentati circa 50 milioni di anni fa [5]. In generale esistono numerose testimonianze molecolari di un continuo flusso genico tra virus e organismi viventi, uomo incluso:

1) Basandosi sulle similitudini esistenti tra le proteine dell'apparato replicativo dei virus, dei batteri e degli eucarioti, è stato proposto che l'apparato per la conversione dell'RNA in DNA sia emerso nei virus (trascrittasi inversa) e poi "passato" alle cellule a RNA, avviando così il processo che ha stabilito il DNA come materiale genetico ereditabile comune a tutti gli esseri viventi [6].

2) E' stata avanzata l'ipotesi che il nucleo della cellula eucariote derivi da un virus dotato di tunica (simile al poxvirus), basandosi sull'osservazione che questi virus durante la trascrizione intracellulare formano degli pseudonuclei utilizzando le membrane interne della cellula infetta [7].

3) L'apparato replicativo e la RNA polimerasi dei mitocondri derivano da un proto-batteriofago (virus batterico) il cui DNA era integrato nel proto-procariote (simbionte intracellulare) che ha originato i mitocondri [8].

\section{POTENZIALE EPIDEMICO E PANDEMICO DEI VIRUS PATOGENI PER L'UOMO}

Il fatto che i virus infettino tutte le specie viventi e quindi siano strettamente legati all'ecologia degli organismi che li ospitano, è in 
grado di spiegare il fenomeno dell' "emergenza" di virus all'interno di popolazioni di nuovi ospiti. Ad esempio, tutti i virus che infettano l'uomo derivano da virus animali, adattatisi all'ospite umano. La definizione di "emergente" per un virus, quindi, è sempre relativa ad un preciso contesto geografico e temporale. In epoche diverse, cioè, ogni virus è stato "emergente". Il virus dell'epatite B è entrato nella popolazione umana dalle scimmie oltre 100.000 anni fa. Il virus del morbillo, invece, deriva da quello della peste bovina, passato all'uomo all'epoca dei primi allevamenti di bovini domestici nel neolitico, circa 10.000 anni fa. Per tutta la storia dell'uomo, quindi, si è avuta l'introduzione di nuovi virus. Tra i più recenti, entrati negli ultimi 100 anni, ricordiamo HIV, Ebola, il coronavirus della SARS, il virus dell'influenza aviaria H5N1 [1].

Il meccanismo è sempre lo stesso: l'uomo colonizza un ambiente modificandone l'ecologia e quindi entrando in contatto con nuove specie animali, portatrici di virus, che, grazie alla loro grande capacità di adattamento, possono diventare capaci di infettare l'uomo.

Un tipico esempio è il virus Ebola. Il suo serbatoio naturale sono pipistrelli equatoriali che si nutrono di frutta, a cui il virus è ben adattato e non causa nessuna patologia. Tramite il guano o la macellazione a scopo alimentare, il virus può occasionalmente passare all'uomo, causando un'infezione che può essere mortale in oltre l' $80 \%$ dei casi. Tuttavia, proprio a causa della stretta relazione tra pipistrelli e virus, Ebola è confinato ai paesi Africani della fascia equatoriale. L'infezione dell'uomo è sempre accidentale e conseguente alle pratiche di caccia di animali selvatici, sia pipistrelli che primati, anche loro infettabili dai pipistrelli, e la conseguente macellazione con contatto con sangue infetto. Anche la diffusione del virus durante le epidemie è spesso conseguenza di comportamenti umani: ad esempio i riti funebri locali con esposizione pubblica dei morti per Ebola, altamente infettivi, che vengono lavati, toccati e baciati da decine di persone [9].

Molti virus possono essere trasmessi da vettori artropodi, come le zanzare. In questo caso, la diffusione di questi virus in nuovi areali è una diretta conseguenza dei cambiamenti nell'ecologia dei vettori. Un caso tipico è quello della zanzara tigre, Aedes albopictus. La sua diffusione dall'Asia alle zone temperate dell'area mediterranea ha aperto la possibilità a molti virus esotici, quali Zika, Chikungunya, Dengue, di causare episodi epidemici anche nei nostri paesi [10].

L'introduzione di nuovi virus in una popolazione suscettibile, ovvero che non ne ha mai fatto esperienza immunologica, può avere 
effetti devastanti. Nel 1875, la prima epidemia di morbillo nelle isole Fiji, dove il virus era sconosciuto, ha causato oltre 50.000 vittime, un terzo della popolazione. Il virus era stato importato dal re e dai suoi dignitari che si erano recati in Australia in visita diplomatica e avevano contratto la malattia.

Anche le pandemie influenzali possono avere effetti importanti. Ricordiamo l'influenza Spagnola del 1918-19 che causò oltre 70 milioni di morti. I virus influenzali hanno come serbatoio naturale gli uccelli migratori anseriformi (anatre, cigni e congeneri). Da questi animali il virus è passato a tutti i mammiferi. Quando un virus aviario e uno umano coinfettano uno stesso ospite possono rimescolare i loro geni, generando varianti virali totalmente nuove. L'ospite classico è il suino, uno dei pochi organismi in grado di venire infettato contemporaneamente da virus aviari, suini e umani. I virus responsabili delle cinque pandemie influenzali degli ultimi 100 anni si sono tutti generati per riassortimento genico nei suini di allevamento, da cui sono passati all'uomo [11].

In generale, quando un nuovo virus entra in una popolazione, si possono stabilire diversi equilibri, in relazione al grado di suscettibilità immunologica degli individui. Si distinguono quattro tipi principali di interazione virus-ospite:

1) Interazione stabile: il virus si mantiene nella popolazione ospite per periodi indefiniti, in presenza di condizioni dell'ecosistema stabili.

2) Interazione dinamica: i cambiamenti nell'ecosistema o mutazioni geniche possono favorire l'introduzione di un virus in una nuova popolazione ospite (salto di specie).

3) Interazione a vicolo cieco: il virus occasionalmente infetta un ospite diverso da quello naturale, ma non avvia un nuovo ciclo stabile.

4) Interazione non permissiva: il virus non riesce ad infettare una data popolazione (pertanto definita non suscettibile)

\section{L'ATTUALE PANDEMIA CAUSATA DAL VIRUS HIV-1: L'AIDS}

Sebbene i mezzi di comunicazione spesso enfatizzino eventi epidemici di virus "esotici" come Ebola o Zika, in realtà il principale killer mondiale è il virus HIV-1, responsabile della pandemia di AIDS, la sindrome da immunodeficienza acquisita [12]. Oltre 35 milioni di persone nel mondo hanno contratto il virus, che causa oltre un milione di morti ogni anno e altrettante nuove infezioni. 
Il virus HIV-1 appartiene al gruppo dei retrovirus, così indicati in quanto sono in grado di convertire il loro genoma a RNA in una molecola di DNA a doppio filamento, che viene poi fisicamente integrata nei cromosomi della cellula infetta. In questo modo i geni virali diventano parte del patrimonio genetico della cellula. In questa condizione, la cellula infetta è sempre potenzialmente in grado di produrre nuovi virus, ma può anche permanere in questa condizione, definita come infezione latente, per lungo tempo senza provocare alcuna reazione da parte del sistema immunitario. La maggior parte delle cellule infette iniziano subito a trascrivere e tradurre i geni virali, rilasciando nuovi virioni che alimentano così l'infezione. La conseguenza è la distruzione della cellula da parte del sistema immunitario o la sua morte a causa dell'effetto citopatico della replicazione virale. Una quota di cellule infette, tuttavia, permane in uno stato di infezione latente, costituendo un serbatoio permanente da cui il virus può emergere in qualsiasi momento. Questo è il motivo per cui non è possibile, ad oggi, eradicare il virus dall'organismo infetto.

Il bersaglio preferenziale del virus HIV-1 sono i linfociti T helper che presentano alla loro superficie il recettore CD4. Queste cellule hanno la funzione fondamentale di attivare le difese immunitarie che contrastano le infezioni. L'infezione da virus HIV-1 decorre in maniera del tutto asintomatica anche per 10-15 anni, ma la deplezione ad opera del virus di queste cellule T CD4 causa nel tempo una grave forma di deficienza immunitaria, l'AIDS, che causa l'instaurarsi di infezioni da parte di patogeni opportunisti. L'AIDS è una malattia mortale.

Oggi grazie alla terapia farmacologica possiamo evitare che un paziente sviluppi la fase di AIDS conclamato per cui, pur rimanendo sempre infetto, entra in una fase di cronicizzazione della malattia che ne garantisce una sopravvivenza ormai paragonabile a quella della popolazione non infetta. Tuttavia la terapia va assunta per tutta la vita e va iniziata idealmente prima di sviluppare l'immunodeficienza. Quest'ultimo punto è cruciale, soprattutto considerando che in molti casi l'infezione viene diagnosticata alla comparsa dei sintomi, quindi anni dopo l'infezione. In Italia ogni anno si infettano 4000 persone, ma questi casi per il $70 \%$ si riferiscono a infezioni diagnosticate in fase avanzata. Si stima che oltre 15.000 persone vivano nel nostro paese senza sapere di avere il virus HIV-1, contribuendo a diffonderlo. Il virus nei nostri paesi si trasmette in oltre l' $80 \%$ dei casi tramite rapporti sessuali non protetti. Quindi solo l'utilizzo del preservativo è in grado di limitarne la diffu- 
sione e solo la consapevolezza del rischio è in grado di guidare il paziente ad effettuare il test sierologico per verificare se è infetto. Attualmente è disponibile un test per autodiagnosi acquistabile in farmacia e in grado di fornire una risposta in 20 minuti. Se una persona ha contratto il virus, deve rivolgersi al medico in modo che, al momento opportuno, possa iniziare la terapia, bloccando così il progredire della malattia.

\section{PREVENZIONE E TERAPIA DELLE INFEZIONI VIRALI: I VACCINI}

L'arma più efficace per contrastare il diffondersi delle epidemie virali sono i vaccini [13].

Quando un agente patogeno, virus, batterio o protozoo, invade le cellule del nostro organismo, si attiva una complessa serie di eventi molecolari che portano all'attivazione del sistema immunitario. Cellule specializzate, come ad esempio le cellule dendritiche, sono in grado di fagocitare l'agente patogeno e processare le sue proteine generando corti peptidi che vengono poi esposti alla superficie complessati a speciali recettori e agiscono da antigeni. Queste cellule presentanti l'antigene o APC, sono in grado di spostarsi dal sito dell'infezione per andare ad incontrare altri elementi del sistema immunitario, in particolare $i$ linfociti T helper. Questi sono dotati di speciali recettori alla loro superficie, in grado di riconoscere uno degli antigeni presenti sulle APC, formando così un complesso cellula-cellula. Come conseguenza, vengono rilasciate molecole di segnale come chemochine e citochine, che attivano altre cellule specializzate tra cui i linfociti $T$ citotossici e i linfociti $B$. I primi sono in grado di aggredire le cellule infette che espongono alla loro superficie l'antigene corrispondente e distruggerle, mentre i linfociti B producono anticorpi in grado di legarsi specificamente all'agente patogeno che possiede l'antigene che le ha stimolate, neutralizzandolo. Una parte dei linfociti B che producono questi anticorpi specifici permane nell'organismo sotto forma di cellule di memoria. In occasione di un successivo incontro con lo stesso agente infettivo che le ha stimolate, queste cellule sono rapidamente in grado di produrre anticorpi contro di esso, bloccandone la diffusione. Al primo incontro con il patogeno la risposta immunitaria diviene pienamente efficace dopo due o tre settimane, mentre la seconda volta le cellule di memoria si attivano nel giro di pochi giorni. Il principio su cui si basa la vaccinazione è proprio quello di stimolare la memoria immunologica nei confronti di un agente 
patogeno, senza però provocare la malattia. Esponendo l'organismo ad un virus o batterio attenuato o inattivato, così come agli antigeni purificati, si innesca la stessa cascata di segnali che verrebbe attivata in caso di infezione, portando così alla formazione di una popolazione di cellule di memoria. In questo modo, quando la persona vaccinata viene a contatto con il vero agente infettivo, il suo sistema immunitario è già "preavvertito" e quindi in grado di neutralizzare rapidamente l'aggressore, prima che questo abbia modo di diffondersi nell'organismo provocando la malattia.

Una cosa importante da ricordare è che la vaccinazione non protegge solo l'individuo che la fa, ma rappresenta uno strumento fondamentale per limitare la diffusione di malattie infettive all'interno della popolazione. E' il concetto della cosiddetta immunità di gruppo. Ogni agente infettivo, ad esempio un virus, è caratterizzato da uno specifico parametro detto numero di riproduzione o $\mathrm{R}_{0}$. Questo numero riflette la capacità infettiva di un agente trasmissibile e, nella sua essenza, indica il numero di individui che possono contrarre la malattia a partire da una singola persona infetta. L'influenza ha un $\mathrm{R}_{0}$ pari a 3-4, mentre il morbillo pari a 18. Questo vuol dire che, mediamente, una persona affetta da influenza può infettare 3-4 persone, mentre chi ha il morbillo può passare la malattia a circa 18 persone. $\mathrm{O}$, in altre parole, che il morbillo è molto più infettivo dell'influenza. Questi valori si riferiscono ad una popolazione "ideale" in cui tutti gli individui siano ugualmente suscettibili al virus. Ma se adesso immaginiamo che una percentuale significativa delle persone sia immune all'infezione, allora il singolo paziente avrà una probabilità inferiore di entrare in contatto con un individuo che possa contrarre la malattia. Lo scopo delle vaccinazioni di massa è proprio questo: aumentare il grado di immunità generale all'interno della popolazione, così che, anche nell'evento che qualcuno si ammali, l'agente patogeno non possa diffondersi causando un'epidemia, trovandosi di fronte un "muro" di persone immuni. In generale, una quota di persone immuni pari o superiore al $95 \%$ è in grado di evitare il diffondersi di qualunque malattia infettiva. L'immunità di gruppo è molto importante per garantire la protezione delle persone che per motivi di età o salute non possono vaccinarsi.

Grazie alla vaccinazione mondiale, il vaiolo, che nei secoli si stima abbia causato oltre mezzo miliardo di vittime, è stato completamente eradicato in tutto il mondo. Ma ovunque si siano attuate vaccinazioni di massa, le malattie causate dai virus contro cui viene indotta l'immunità 
si sono ridotte del 90-99\%, o addirittura in alcuni casi sono totalmente scomparse, come la poliomielite che persiste ancora in solo poche nazioni del mondo.

\section{CONCLUSIONI}

Studiare l'evoluzione e le dinamiche delle popolazioni virali riveste un interesse non solo per la salute pubblica, ma anche per la comprensione delle complesse relazioni tra i viventi, così come è in grado di offrire una chiave per lo studio di molti fenomeni biologici. Oggi sono note alla scienza meno di un millesimo delle specie virali che si stima esistano nella biosfera. Le nuove tecnologie biomolecolari, come la metagenomica, la proteomica e la biologia dei sistemi, offrono sempre migliori strumenti per caratterizzare nuove specie virali, predirne il potenziale patogenetico e identificare all'interno del ciclo vitale dei virus patogeni bersagli per approcci chemio- e immuno-terapici.

\section{BIBLIOGRAFIA}

1. Maga G., Occhio ai Virus (2012). Chiavi di Lettura, Zanichelli Ed. (Bologna).

2. Dimmock N.J., Easton A.J., Leppard K.N., Introduzione alla Virologia Moderna (2017). Casa Editrice Ambrosiana (Milano).

3. Harper D.R., Virus (2013). Zanichelli Ed. (Bologna).

4. Zarate S., Taboada B., Yocupicio-Monroy, M., Arias C.F., Human Virome (2017). Arch. Med. Res. 48:701-706.

5. Mi S., Lee X., Li X., Veldman G.M., Finnerty H., Racie L., La Vallie E., Tang X.Y., Edouard P., Howes S., Keith J.C., McCoy J.M., Syncytin is a captive retroviral envelope protein involved in human placental morphogenesis (2000). Nature 403: 785-789.

6. Cojocaru R., Unrau P.J., Transitioning to DNA genomes in an RNA world (2017). Elife 6: e32330.

7. Martin W.F., Garg S., Zimorski V., Endosymbiotic theories for eukaryote origin (2015). Philos. Trans. R. Soc. Lond. B Biol. Sci. 370: 20140330.

8. Shutt T.E., Gray M.W., Bacteriophage origins of mitochondrial replication and transcription proteins (2006). Trends Genet. 22: 90-95.

9. Coltart C.E., Lindsey B., Ghinai I., Johnson A.M., Heymann D.L., The Ebola outbreak 2013-2016: old lessons for new epidemics (2017). Philos. Trans. R. Soc. Lond. B Biol. Sci. 372: 20160297.

10. Huntigton M.K.m Allison J., Nair D., Emerging vector-borne diseases (2016). Am. Fam. Physician 94: 551-557. 
11. Bavagnoli L., Maga G., The 2009 influenza pandemic: promising lessons for antiviral therapy for future outbreaks (2011). Curr. Med. Chem. 18: 5466-5475.

12. Maga G, AIDS: la Verità Negata (2015). Il Pensiero Scientifico Ed. (Roma).

13. Rappuoli R., Vozza L., I vaccini dell'era globale (2009). Chiavi di Lettura, Zanichelli Ed. (Bologna). 